\title{
COMUNICAÇÃO PÚBLICA DA CIÊNCIA NO BRASIL E URUGUAI DURANTE $O$ SÉCULO XX: ENTRE FORMAÇÕES E GÊNE- ROS DISCURSIVOS
}

\author{
PHILLIPP DIAS GRIPP \\ UNIVERSIDADE FEDERAL DE SANTA MARIA \\ SANTA MARIA, RIO GRANDE DO SUL, BRASIL \\ E-MAIL: PHIDGRIPP@HOTMAIL.COM
}

HTTP://DX.DOI.ORG/10.5902/2316882X22504 
COMUNICAÇÃO PÚBLICA DA CIÊNCIA NO BRASIL E URUGUAI DURANTE O SÉCULO XX: ENTRE FORMAÇÕES E GÊNEROS DISCURSIVOS

Resumo: A dissertação analisou os sentidos e mudanças no discurso sobre a especialidade científica agropecuária durante o século XX, veiculado pelas publicações da ARCO (Bagé, RS), desde 1942, e da La Propaganda Rural (Montevidéu, UY), desde 1901. O trabalho cons-tatou a existência dos gêneros qualificativo, prescritivo, técnico e informativo-científico e que as transformações na prática discursiva estão associadas ao início da produção por jornalistas.

Palavras-chave: Discurso; Popularização científica; História da mídia.

COMUNICACIÓN PÚBLICA DE LA CIENCIA EN BRASIL Y URUGUAY DURANTE EL SIGLO XX: ENTRE FORMACIONES Y GÉNEROS DISCURSIVOS

Resumen: La tesis analizó los sentidos y cambios en el discurso sobre la especialidad científi-ca agropecuaria durante el siglo XX, producido por las publicaciones de la ARCO (Bagé, RS) desde 1942, y de La Propaganda Rural (Montevideo, UY), desde 1901. El trabajo constató la existencia de los géneros calificativo, prescriptivo, técnico y informativo-científico y que los cambios en la práctica discursiva se asocian con el inicio de la producción por los periodistas.

Palabras clave: Discurso; Popularización científica. Historia de los medios.

PUBLIC COMMUNICATION OF SCIENCE IN BRAZIL AND URUGUAY DURING THE 2OTH CENTURY: BETWEEN DISCURSIVE FORMATIONS AND GENRES

Abstract: The dissertation analyzed the meanings and changes in discourse of farming and agriculture scientific specialty during the 20th century, conveyed by the journals ARCO (Ba-gé, RS), since 1942, and La Propaganda Rural (Montevideo, UY), since 1901. It was found the existence of qualifying, prescriptive, technical and scientific-informative genres and that discoursive practice transformations are allied to the beginning of journalistic production.

Keywords: Discourse. Scientific Popularization. Media History.

\section{INTRODUÇÃO}

Rev.Cad. Comun. Santa Maria, v.20, n.2, art 8, p.2 de 9, maio/ago.2016 
Os saberes relacionados à temática campeira estão no cerne da formação sócio-cultural-econômica e histórica da região Platina, a qual é formada pelos países banhados pela Bacia do Rio da Prata, Argentina, Uruguai, Paraguai e a região sul do Brasil e da Bolívia. Para além das fronteiras demarcadas através de lutas armadas e acordos diplomáticos entre os impérios português e espanhol, a região apresenta singularidades identitárias relacionadas ao contexto agropecuário, conforme sustenta Darcy Ribeiro (1995), que percebe tais traços desde sua colonização até ações cotidianas dos sujeitos que ali vivem, como o hábito de tomar chimarrão, preparar o charque, usar vestimentas próprias à cultura gaúcha/ gaucha, entre outras.

Nesse cenário, o presente trabalho atentou ao âmbito dos saberes científicos e tecnoló-gicos, considerando a difusão de informações especializadas como uma via para a populariza-ção científica, permitindo a aplicabilidade do conhecimento, reflexões acerca dos novos sabe-res e prestação de contas sobre o financiamento público ao desenvolvimento das pesquisas. Levando em conta a histórica formação da região platina em relação à especialidade agrope-cuária, objetivou-se investigar os sentidos e as mudanças ocorridas nas formas de comunicar publicamente os saberes científicos da área no Brasil e no Uruguai no decorrer do século $\mathrm{XX}$.

Assim, esta pesquisa se apoiou na Análise do Discurso de origem francesa para apre-ender os gêneros discursivos (CHARAUDEAU, 2013) produzidos e as mudanças nas regula-ridades discursivas que permitem situar as publicações em diferentes formações discursivas (FOUCAULT, 2008; PÊCHEUX 1997) durante o período de análise. Essa abordagem se am-para em dois periódicos pautados pela temática rural, desde o início de suas respectivas veicu-lações na primeira metade do século XX até a década de 1990: 1) as publicações trimestrais da Associação Brasileira de Criadores Ovinos (ARCO), desde o ano de fundação da instituição, em janeiro de 1942, com sede em Bagé (cidade fronteiriça do Rio Grande do Sul), que circulam em todo o Brasil; e 2) a revista mensal, independente e comercial, La Propaganda Rural, desde dezembro de 1901, com sede em Montevidéu (UY) e com circulação no Uru-guai, sul do Brasil, Argentina e Paraguai. 


\section{APORTE TEÓRICO-METODOLÓGICO}

A existência e continuidade das publicações da ARCO e de La Propaganda Rural, considerando as mudanças em suas discursividades textuais, ressaltam a relevância da análise que visa entender quais sentidos esses periódicos visibilizaram no século XX. Entende-se que tais modificações são possibilitadas por relações de poder (FOUCAULT, 2008; 1979), as quais se estabelecem na sociedade de forma inconsciente, fazendo-a funcionar num sistema em que os sujeitos não detêm o poder, apenas o exercem através da produção discursiva.

Tais discursos são entendidos por Foucault (2008) como conjuntos de enunciados ori-entados por formações discursivas. Para Pêcheux (1997), por sua vez, estas são ainda condici-onadas pelas ideologias dos sujeitos, logo, são estruturadas por formações ideológicas. Dessa forma, estre trabalho parte da premissa de que em uma formação ideológica dada, são consti-tuídas uma ou mais formações discursivas que delineiam quais regras os enunciados devem obedecer para serem estruturados em um período.

Pela reflexão de Foucault (2014), considera-se que os sujeitos nutrem uma vontade de saber, pois têm desejo de exercer o poder através da produção de discursos considerados ver-dadeiros. Nesse panorama, optou-se por caracterizar a vontade de saber como uma formação ideológica, pois ela orienta diferentes formações discursivas sobre a temática científica. Neste trabalho, adotou-se os conceitos de comunicação científica, divulgação científica e jornalismo científico como formações discursivas, já que cada um obedece a diferentes sistemas de dis-persão: difundem a temática científica a diferentes públicos e a partir de diferentes regras. A comunicação científica tem uma abordagem técnica e é direcionada a especialistas, a divulga-ção científica produz enunciados inteligíveis a não-especialistas e o jornalismo científico con-diciona a produção textual à prática jornalística, conforme explica Bueno (2009).

Compreende-se ainda que as formações de divulgação científica e de jornalismo cien-tífico possibilitam que a ciência seja popularizada, permitindo que sujeitos não-especialistas entendam o assunto e participem das relações de poder no âmbito da ciência. Por este viés, propôs-se entender a popularização científica como um dispositivo (FOUCAULT, 1979), pois ela se estrutura como uma via para não-especialistas assimilarem a

Rev.Cad. Comun. Santa Maria, v.20, n.2, art 8, p.4 de 9, maio/ago.2016 
ciência e se utilizarem das informações para o exercício do poder.

Entende-se ainda que a produção discursiva em âmbito midiático se constitui, de acor-do com Charaudeau (2013), em três lugares numa situação comunicacional: da produção, do produto e da recepção. Dessa forma, a comunicação se organiza em espaços externos, que indicam a intenção do enunciador e a interpretação do destinatário, e internos, que apontam para os efeitos de sentido dos textos, os quais conformam os contratos de comunicação.

Charaudeau (2013) explica que a constituição do contrato depende das condições de identidade (quem diz e para quem), finalidade (para que se diz), propósito (sobre o que se diz) e de dispositivo (em que condições se diz), que compõem os dados externos, e dos espaços de locução (justificativa para dizer), relação (interligação entre enunciador e destinatário) e tema-tização (organização textual), ligados aos dados internos. De acordo com o autor, quando di-ferentes textos apresentam os mesmos dados, eles podem ser agrupados gêneros discursivos.

Com isso, a análise se dividiu em duas partes: 1) identificou-se os dados externos e in-ternos dos textos selecionados, agrupando-os em diferentes gêneros, descritos para compreen-der as possibilidades de sentido; e 2) discutiu-se tais sentidos em relação ao condicionamento às formações discursivas em diferentes períodos do século XX para evidenciar as mudanças ocorridas na prática discursiva através do uso do dispositivo de popularização científica.

\section{ANÁLISE}

Para a análise foram realizadas coletas de dados dos periódicos da ARCO e de La Propaganda Rural em Bagé-RS e em Montevidéu-UY, respectivamente. As coletas foram feitas através de fotografias de textos sobre ciência e tecnologia de todas as edições do primeiro e de seis enunciados por ano do segundo, devido à grande quantidade de edições deste. A partir desse corpus inicial, definiu-se o recorte de três textos por década desde o início da produção das respectivas publicações até a década de 1990, para realizar os procedimentos de análise, sendo assim: 30 da La Propaganda Rural e 15 da ARCO, totali-zando 45 textos.

Os enunciados foram lidos isoladamente e categorizados em quatro diferentes gêneros discursivos, denominados como: a) qualificativo

Rev.Cad.Comun. Santa Maria, v.20, n.2, art 8, p.5 de 9, maio/ago.2016 
(12 textos), que se limita a descrever particu-laridades de espécies; b) prescritivo (16 textos), que indica e descreve como realizar um pro-cedimento; c) técnico (10 textos), que se utiliza de argumentos teórico-metodológicos para explicar como uma pesquisa foi desenvolvida; e d) informativo-científico (07 textos), que estrutura uma narrativa para informar sobre acontecimentos que podem incidir diretamente no cotidiano dos sujeitos do campo.

Para abranger o uso do dispositivo de popularização científica, procurou-se perceber se os enunciados eram inteligíveis a sujeitos não-especialistas através da presença de três eixos: 1) explicações sobre as terminologias técnicas presentes; 2 ) contextualização do cenário teórico-metodológico utilizado pelo pesquisador ao cotidiano de não-especialistas; e 3) debate crítico e sócio-político sobre as informações científicas.

Durante a leitura dos enunciados e categorização dos gêneros, constatou-se que os tex-tos não apresentam os três eixos em suas totalidades, mas se percebeu algumas mudanças na prática discursiva adotada na estrutura de enunciados a partir do momento em que as revistas passaram a ser produzidas pelas equipes editoriais de jornalistas, com aparecimento do gênero informativo-científico. Assim, consta-se que os enunciados pertencentes aos gêneros qualifi-cativo, prescritivo e técnico foram produzidos por especialistas durante todo o século XX.

No período que vai de 1901 a 1960 e posteriormente de 1985 a 1999 em La Propa-ganda Rural e de 1942 a 1970 nas publicações da ARCO, a produção enunciativa era feita exclusivamente por especialistas. Os enunciados veiculados nessas temporadas apresentam uma linguagem demasiadamente técnica, sem contextualizações sobre a abordagem teórico-metodológica aos sujeitos não-especialistas, e, principalmente, sem uma reflexão crítica e sócio-política acerca da ciência, o que dificulta sobremaneira a compreensão do discurso, tor-nando os textos dificilmente inteligíveis a estes sujeitos. Disso decorre que os enunciados não se condicionam ao dispositivo de popularização e o exercício das relações de poder fica restri-to à comunidade de cientistas, tendo em vista que os enunciados dos gêneros qualificativo, prescritivo e técnico obedecem à ordem da formação de comunicação científica, importando-se com uma produção discursiva dirigida apenas aos sujeitos especialistas.

No decorrer do século XX, em La Propaganda Rural os jornalistas

Rev.Cad. Comun. Santa Maria, v.20, n.2, art 8, p.6 de 9, maio/ago.2016 
começaram a pro-duzi-la em 1960 até 1985 e nas publicações da ARCO contaram com tais profissionais de 1970 até 1989. Nestes momentos percebe-se a insurgência do gênero informativo-científico, que apresenta uma estrutura enunciativa mais fluida por meio da organização textual narrativa e mediação feita por jornalistas das informações concedidas pelos especialistas.

O gênero informativo-científico é próprio à formação discursiva de jornalismo cientí-fico, ao considerar que ele se atém à necessidade de informar sobre acontecimentos com pro-babilidade de incidirem diretamente no contexto social dos sujeitos do campo. Entretanto, a sua regularidade de construção enunciativa e de sentido do gênero não se condiciona ao dis-positivo de popularização científica, tendo em vista não cumprir totalmente os requisitos para promover um discurso inteligível aos não-especialistas.

Compreende-se que o período no qual os jornalistas assumem a produção de La Pro-paganda Rural e das publicações da ARCO se configura como um momento de mudanças não apenas do corpo editorial, passando de especialistas a jornalistas, mas também na prática discursiva das revistas. Não se pode considerar que esses discursos apropriam-se devidamente e em suas totalidades do dispositivo de popularização científica, mas se percebe um cuidado com a produção enunciativa por parte da equipe editorial jornalística, que apresenta textos mais fluidos através de estrutura organizacional narrativa. Tal momento, portanto, é encarado como uma fase de transição, um período em que o uso do dispositivo de popularização cientí-fica começa a ser evidenciado na prática discursiva adotada pelas revistas analisadas, visando contribuir para o exercício democrático das relações de poder no âmbito da comunicação pú-blica da ciência por especialistas e não-especialistas. Logo, em La Propaganda Rural no perí-odo que vai de 1960 até 1985 e nas publicações da ARCO entre 1970 e 1989, percebe-se um condicionamento duplo à formação de jornalismo científico e de comunicação científica, ten-do em vista a produção dos quatro gêneros evidenciados e considerando suas respectivas par-ticularidades de efeitos de sentido.

Rev.Cad.Comun. Santa Maria, v.20, n.2, art 8, p.7 de 9, maio/ago.2016 


\section{CONSIDERAÇÕES FINAIS}

Ao identificar enunciados dos gêneros qualificativo, prescritivo, técnico e informativo-científico nos periódicos da ARCO e em La Propaganda Rural, percebe-se similaridades na prática discursiva das publicações ao longo do século XX. Tais semelhanças demonstram a opção por visibilizar discursos embasados no contexto sócio-econômico-cultural e histórico comum, relacionado à agropecuária, da região Platina.

A pesquisa constatou que as mudanças ocorridas nas construções de sentidos que vis-lumbram os primórdios do uso do dispositivo de popularização científica estão diretamente relacionadas às novas equipes editoriais compostas por jornalistas, que passam a produzir a La Propaganda Rural em 1960 e as publicações da ARCO em 1970. Nesse período, pode-se notar certa preocupação em tornar os enunciados inteligíveis por meio do gênero informativo-científico, com algumas tentativas de explicações de terminologias técnicas, de contextualiza-ções da abordagem teórico-metodológica ao cotidiano de não-especialistas e de promoções de debates críticos e sócio-político sobre as produções científicas. Essa conjuntura é entendida como esforços dos jornalistas que visam transformações no estado de dominação evidente no âmbito dos saberes científicos entre especialistas e não-especialistas para um exercício demo-crático das relações de poder, por meio do dispositivo de popularização científica.

\section{REFERÊNCIAS}

BUENO, W. C. Jornalismo científico: revisitando o conceito. In: VICTOR, C. et al. (Orgs.). Jornalismo científico e desenvolvimento sustentável. São Paulo: All Print, 2009.

HARAUDEAU, P. Discurso das mídias. 2ed. São Paulo: Contexto, 2013.

FOUCAULT, M. A arqueologia do saber. 7ed. Rio de Janeiro: Forense Universitária, 2008.

. A ordem do discurso. São Paulo: Loyola, 2013.

. Aulas sobre a vontade de saber. São Paulo: WMF Martins Fontes, 2014.

. Microfísica do poder. Rio de Janeiro: Graal, 1979.

PÊCHEUX, M. Semântica e discurso: uma crítica à afirmação do óbvio. $3^{\text {a }}$ ed. Campi-

Rev.Cad. Comun. Santa Maria, v.20, n.2, art 8, p.8 de 9, maio/ago.2016 
nas: Unicamp, 1997.

RIBEIRO, D. O povo brasileiro: a formação e o sentido do Brasil. $2^{\text {a }}$ ed. São Paulo: Compa-nhia das letras, 1995.

\section{Phillipp Dias Gripp}

Doutorando pelo Programa de Pós-Graduação em Comunicação da Universidade Federal de Santa Maria. Mestre em Comunicação pela mesma instituição (2016). Integrante do Grupo de Pesquisa Comuni-cação, identidades e fronteiras. E-mail: phidgripp@gmail.com.

A dissertação que originou este artigo foi orientada pela profa. Ada Cristina Machado da Silveira e defendida em 18/02/2016, na linha "Mídias e identidades contemporâneas" do POSCOM-UFSM.

RECEBIDO EM: 05/06/2016

ACEITO PARA PUBLICAÇÃO: 20/06/2016

Rev.Cad.Comun. Santa Maria, v.20, n.2, art 8, p.9 de 9, maio/ago.2016 